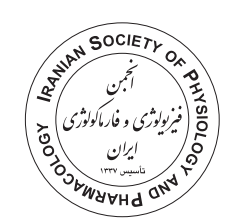

\title{
Atorvastatin enhances the antitumor activity of tamoxifen in B16f10 mouse melanoma cell lines
}

9. Maryam Malek ${ }^{1}$, Maedeh Ghasemi ${ }^{1}$, Golnaz Vaseghi ${ }^{2}$, Ahmad Ghasemi $^{1}$, Hajar Naji Esfahani ${ }^{3}$, Nasim Dana ${ }^{3}$, Shaghayegh Haghjooy Javanmard ${ }^{3 *}$ (D)

1. Department of Physiology, School of Medicine, Isfahan University of Medical Sciences, Isfahan, Iran

2. Isfahan Cardiovascular Research Center, Cardiovascular Research Institute, Isfahan University of Medical Sciences, Isfahan, Iran

3. Applied Physiology Research Center, Cardiovascular Research Institute, Isfahan University of Medical Sciences, Isfahan, Iran

\begin{abstract}
Introduction: Tamoxifen has been used in the treatment of metastatic malignant melanoma more common with other agents in the combined therapy. Up-regulated activity of the mevalonate pathway has been shown in a range of different cancers. Atorvastatin is the most commonly used statin approved for cholesterol reduction by inhibiting the mevalonate pathway and has been shown to inhibit tumor growth. In the present study, we used atorvastatin and tamoxifen combination therapy on B16f10 mouse melanoma cell lines to study whether atorvastatin could increase the sensitivity of melanoma cells to the chemotherapeutic agent such as tamoxifen.

Methods: The cell line was treated with different concentrations of tamoxifen and/or atorvastatin for 24 and $48 \mathrm{~h}$ and the effects of treatment on p53 and RhoA were investigated using quantitative RT-PCR.

Results: The combination of atorvastatin and tamoxifen resulted in a potentiation antitumor effect via up-regulation of $\mathrm{p} 53$ and down-regulation of RhoA expression against melanoma tumors in vitro. Furthermore, we demonstrated the combination of atorvastatin with tamoxifen could reduce tamoxifen dose to minimize possible detrimental side effects in melanoma.

Conclusion: Our results suggested that atorvastatin as a combined therapy with tamoxifen may provide a new approach for improving the efficacy and treating against melanoma cancer but needs further exploration in clinical trials.
\end{abstract}

\section{Introduction}

Melanoma, the common cancer in the world, is one of the most dangerous cutaneous cancers formed by neoplastic changes of melanocytes and can rapidly be extended to deeper layers of derma as well as other tissues.

\author{
Keywords: \\ Tamoxifen \\ Atorvastatin \\ p53 \\ RhoA
}

Melanoma

\footnotetext{
* Corresponding author: Shaghayegh Haghjooy Javanmard, sh_haghjoo@med.mui.ac.ir Received 25 May 2020; Revised from 13 September 2020; Accepted 15 September 2020

Citation: Malek M, Ghasemi M, Vaseghi G, Ghasemi A, Naji Esfahani H, Dana N, Haghjooy Javanmard S. Atorvastatin enhanced the antitumor activity of tamoxifen in B16f10 mouse melanoma cell lines. Physiology and Pharmacology 2021; 25: 83-91. http://dx.doi.org/10.32598/ppj.25.1.40
} 
tality rate of melanoma as a life-threatening malignancy remains unchanged and patients with metastatic melanoma have a median survival time of only 6-9 months (Tarhini and Agarwala, 2006). Tamoxifen is an estrogen receptor antagonist that is routinely used in advanced melanoma therapy but as a single agent is minimally active in treating patients with melanoma (Rusthoven, 1998; Toma et al., 1999). Combination therapies using selected drugs in order to improving tamoxifen efficacy have recently garnered attention. The safety and efficacy of tamoxifen with combination of other medications may be changed the outcome of therapy in patients. A growing body of preclinical studies have shown that statins may possess anticancer activities including cell cycle arrest, inhibition of angiogenesis and cell proliferation, and anti-metastatic in various types of cancer cells (Barbalata et al., 2020; Beckwitt et al., 2018; Fatehi Hassanabad, 2019). Recent evidence indicates functione al association between the mevalonate pathway in cholesterol metabolism and oncogenic proteins including tumor protein 53 (TP53) and Rho (Freed-Pastor et al., 2012; Ingallina et al., 2018; Parrales et al., 2018) which suggest the efficacy of mevalonate inhibitors or statins in preventing certain malignancies. Rho GTPases are important regulators of actin and microtubule-containing structures and have also been implicated in the control of cell adhesion, cell motility, cell cycle progression and gene expression. The use of statins with modulatory and inhibitory Rho GTPases activities may provide a new and viable therapeutic strategy for melanomas. TP53 is the most frequently mutated gene in cancers which not only deactivates its tumor suppressor function, but also can confer an oncogenic properties with uncontrolled cell proliferation and death (Rivlin et al., 2011). The present study aimed to determine whether statin drugs alters the efficacy of tamoxifen on expression of p53 and Rho in melanoma.

\section{Materials and methods}

\section{Reagents}

Atorvastatin (calcium salt, [C33 H34FN2O5]2Ca $3 \mathrm{H} 2 \mathrm{O}$ ) and tamoxifen were purchased from Darou Pakhsh (Tehran, Iran) and Sobhan Pharmaceutical company (Rasht, Iran) respectively. The Dulbecco's Modified Eagle Medium (DMEM), fetal bovine serum (FBS) and trypsin were obtained from Gibco BRL (Grand Island, NY, USA). Fresh solutions of 1,10 and $100 \mu \mathrm{M}$ ator- vastatin or tamoxifen were prepared in culture medium (from stock solution [1mM] of compounds), whereas the control group was treated with vehicle only.

\section{Tumor cell line and in vitro treatment of melanoma} cells

B16f10 mouse melanoma cell line was obtained from the National Cell Bank of Iran attached to the Pasteur Institute and maintained in culture by serial passages in culture medium composed of natural growth medium DMEM with $10 \%$ FBS, $100 \mathrm{U} / \mu \mathrm{l}$ penicillin and $100 \mu \mathrm{g} /$ $\mu 1$ streptomycin and incubated in the atmosphere with $5 \% \mathrm{CO} 2$. Cells then digested with $0.25 \%$ in trypsin and moved to 96-well plates (1000 cells/well) for 24 and 48 hours treatment with varying doses of tamoxifen (100, 10 and $1 \mu \mathrm{M})$, atorvastatin $(100,10$ and $1 \mu \mathrm{M})$ and combination of $10 \mu \mathrm{M}$ of atorvastatin and different concentrations of tamoxifen $(100,10$ and $1 \mu \mathrm{M})$. All experiments were carried out with ethics committee approval from the Isfahan University of Medical Sciences (IR. MUI.REC.1395.2.230).

Quantitative real-time polymerase chain reaction (qRT-PCR)

Total RNA $(1 \mu \mathrm{g})$ was extracted from the cells with the RNeasy Kit (Thermo Scientific, European Union, Lithuania) and was reverse-transcribed using a RevertAid First Strand cDNA Synthesis kit (Fermentas, Vilnius, Lithuania) according to the manufacturer's instructions. An aliquot $(2 \mu \mathrm{l})$ of reverse transcription product was used for PCR amplification in a total volume of $100 \mu l$. For quantitative PCR analysis, cDNAs were subjected to real time PCR using Maxima SYBR Green/ROX qPCR Master Mix kit (Fermentas, Vilnius, Lithuania) in rotor gene 6000 RT-PCR detection system (Corbett Research, Australia). The PCR primer sets used for RhoA, TP53 and GAPDH cDNA amplification were as follows: RhoA (Hayashi et al., 2005) sense 5'-CTG GTG ATT GTT GGT GAT GG-3', antisense 5'-GCG ATC ATA ATC TTC CTG CC-3'; TP53 (Stanisavljevic et al., 2017) sense 5'-CCCCTCCTGGCCCCTGTCATCTTC-3', antisense 5'-GCAGCGCCTCACAACCTCCGTCAT-3'; GAPDH (Stanisavljevic et al., 2017) sense 5'-GGACCTGACCTGCCGTCTAG-3', antisense 5'-CCACCACCCTGTTGCTGTAG-3'. All samples were analyzed in triplicate and mean values recorded. The level of expression of TP53 and RhoA was 
determined by normalizing the expression of GAPDH

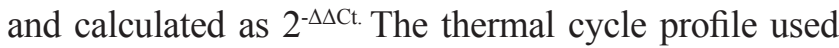
was 40 cycles of denaturation at $95^{\circ} \mathrm{C}$ for $15 \mathrm{~s}$, annealing/extension at $60^{\circ} \mathrm{C}$ for $1 \mathrm{~min}$. Control testing showed that the signal was derived from cDNA for each amplicon and not from primer dimers.

\section{Statistical analysis}

Data were expressed as the mean \pm SEM. Statistical analysis was performed by ANOVA one-way test for multiple comparisons, followed by Tukey post hoc test. Statistically significant values of $\mathrm{P}<0.05$ were considered.

\section{Results}

Effect of tamoxifen and atorvastatin on the expression of p 53

To investigate the effect of tamoxifen and atorvastatin, alone and in combination, on p53 gene expression, B16f10 melanoma cells were treated with different concentrations of drugs for 24 and 48h (Figures. 1a and b). As shown in Figure 1a, no significant changes of p53 expression were observed in the B16f10 cells treated with atorvastatin or tamoxifen and their combinations compared with the control after $24 \mathrm{~h}(\mathrm{~F}(9,26)=5.701)$. Whereas the expression of p53 was significantly increased in B16f10 cells treated with $10 \mu \mathrm{M}$ atorvastatin for durations of $48 \mathrm{~h}$ compared with that in control cells $(\mathrm{F}(9,21)=31.238, P<0.01$; Figure $1 \mathrm{~b})$. Higher doses of tamoxifen $(10$ and $100 \mu \mathrm{M})$ also significantly induced p53 overexpression after $48 \mathrm{~h}(P<0.01)$. After using combined treatment, we found a marked significant increase in p53 expression at lower doses of tamoxifen $(P<0.01)$. For higher dose of tamoxifen $(100 \mu \mathrm{M})$ in combination with atorvastatin, no significant change in p53 expression level was observed.

Our results also showed that the expression of $\mathrm{p} 53$ was markedly higher in the combined treatment group than individual treatments after $48 \mathrm{~h}$ incubation $(P<0.01$; atorvastatin and $1 \mu \mathrm{M}$ tamoxifen compared to $1 \mu \mathrm{M}$ tamoxifen) and $(P<0.01$; atorvastatin and $100 \mu \mathrm{M}$ tamoxifen compared to $100 \mu \mathrm{M}$ tamoxifen).

\section{Effect of tamoxifen and atorvastatin on the expression of RhoA}

We compared the RhoA genomic expression pattern of B16f10 cells cultured with atorvastatin or tamoxifen alone or in combination for 24 or 48 hours relative to GAPDH (Figures. 2a, b). The results were not statistically significant compared to the values of the control group at 24 hours after incubation $(F(9,26)=0.809$; Figure 2a). However, extending the incubation period from 24 to $48 \mathrm{~h}$ reduced the expression of RhoA with atorvastatin $(10 \mu \mathrm{M})$ in comparison to control $(\mathrm{F}(9,24)=2.346$, $P<0.05$; Figure $2 \mathrm{~b}$ ). Higher doses of tamoxifen (10 and $100 \mu \mathrm{M})$ also down-regulated mRNA expression of RhoA after $48 \mathrm{~h}$ incubation $(P<0.05)$. Our results further demonstrated that the combination of atorvastatin/ tamoxifen induced more reduction of RhoA expression with lower doses of tamoxifen $(1$ and $10 \mu \mathrm{M}, P<0.05$; Figure 2b). Interestingly, the expression of RhoA decreased in combination therapy with increasing dose of tamoxifen compared to that in the control cells (Figure $2 b)$.

In addition, a decrease in expression RhoA was observed after 24 and $48 \mathrm{~h}$ of combination therapy (atorvastatin and $100 \mu \mathrm{M}$ tamoxifen) compared with cells treated with $100 \mu \mathrm{M}$ tamoxifen alone $(P<0.05)$.

\section{Discussion}

In the present study, we found that the combination of atorvastatin at effective concentration $(10 \mu \mathrm{M})$ with different doses of tamoxifen potentiates anti-metastasis and also apoptotic effects of tamoxifen in vitro. Combined treatment of atorvastatin with higher dose of tamoxifen may induce toxic effects of drugs as shown with decreased responses. In other words, patients using atorvastatin appear to require a lower dose of tamoxifen for therapeutic aspects on melanoma. Above all, we demonstrated that statins and in particular atorvastatin, could be promising drugs and interest for combination therapy of melanoma because atorvastatin/tamoxifen combination therapy was much stronger than those caused by atorvastatin or tamoxifen individually. Statins are routinely used to treat hyperlipidemia. The importance of this interaction is intensified as atorvastatin may be prescribed with tamoxifen for cancer patients because of hypercholesterolemia. Apart from their lipid-lowering effects, statins have induced anticancer activity in different cancer cell lines (Ibrahim et al., 2019; Tutuska et al., 2020). Therefore, it is necessary to reduce the dose of tamoxifen in these patients due to synergistic drug interaction.

Combination chemotherapy regimens in metastatic 


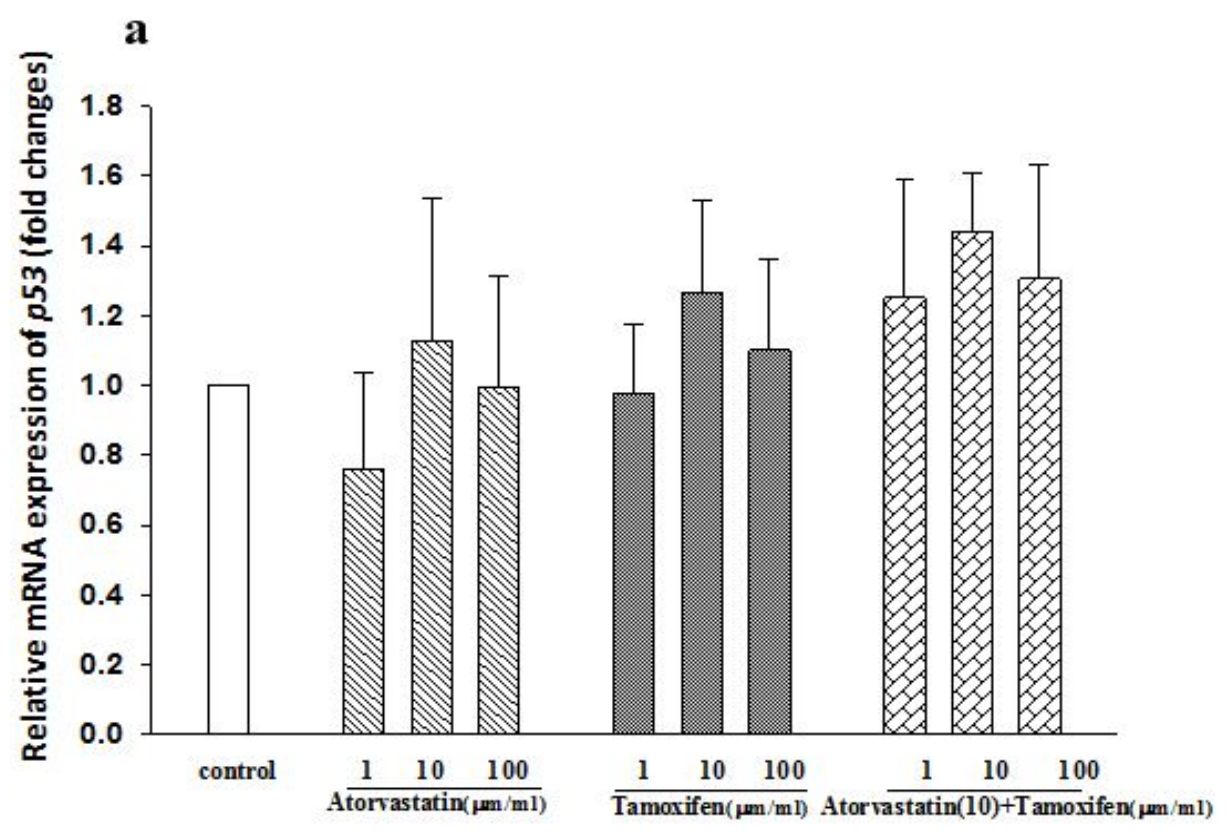

Cells after 24 hours incubation

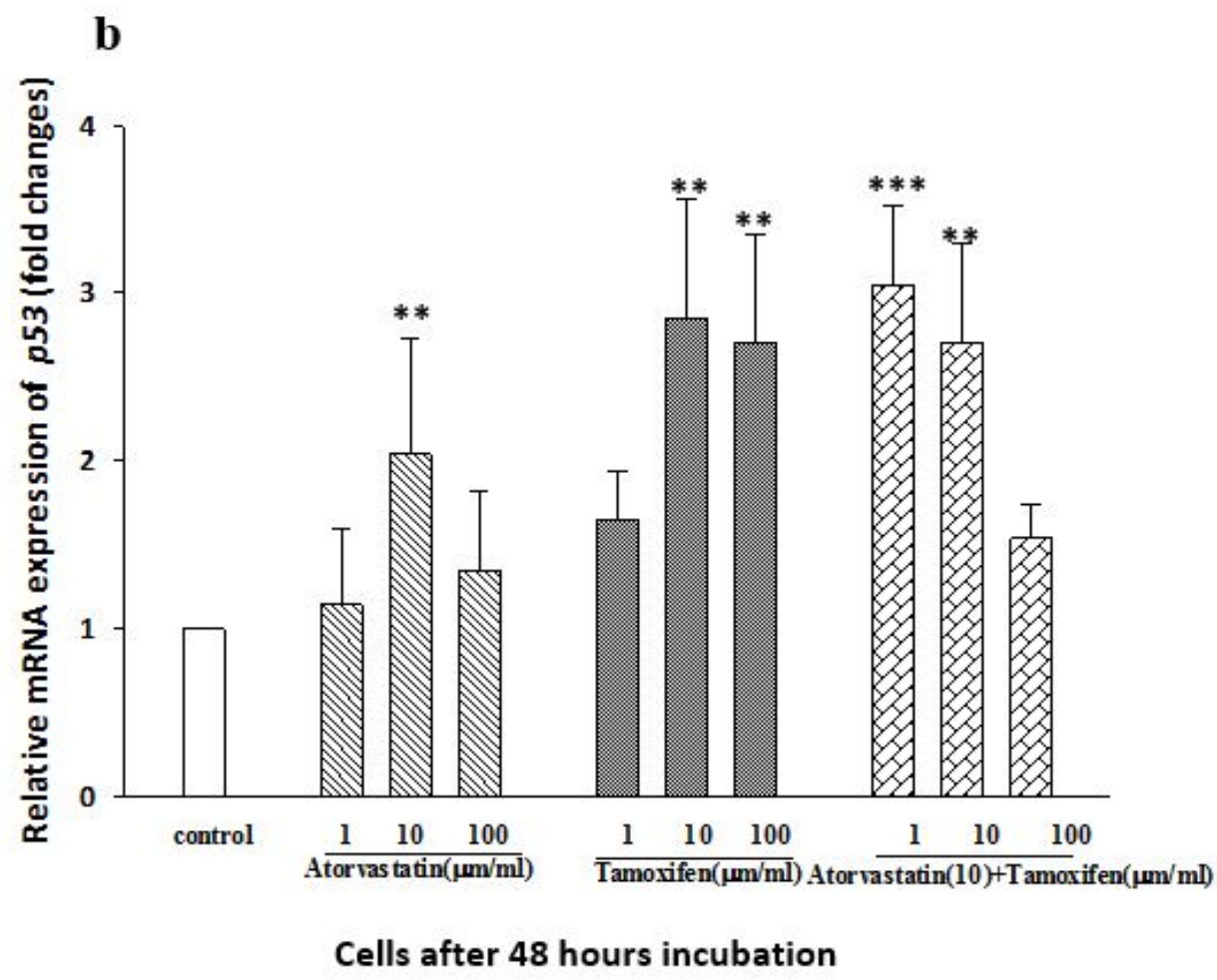

FIGURE 1. Relative mRNA expression for $p 53$ in B16f10 cells. Quantitative real-time PCR was used to measure $p 53$ abundance in cells cultures treated with atorvastatin, tamoxifen or their combination for (a) $24 \mathrm{~h}$ and (b) $48 \mathrm{~h}$. Values are expressed as fold change and $p 53$ gene expression was determined based on the relative levels to non-treated sample (control). The relative expression levels were calculated by the $2^{-\Delta \Delta \mathrm{Ct}}$ method. In all experiments, mRNA abundance was normalized to GAPDH and represents the mean $\pm \operatorname{SEM}(\mathrm{n}=3) .{ }^{* *} P<0.01$ and ${ }^{* * *} P<0.001$ compared with the control. 


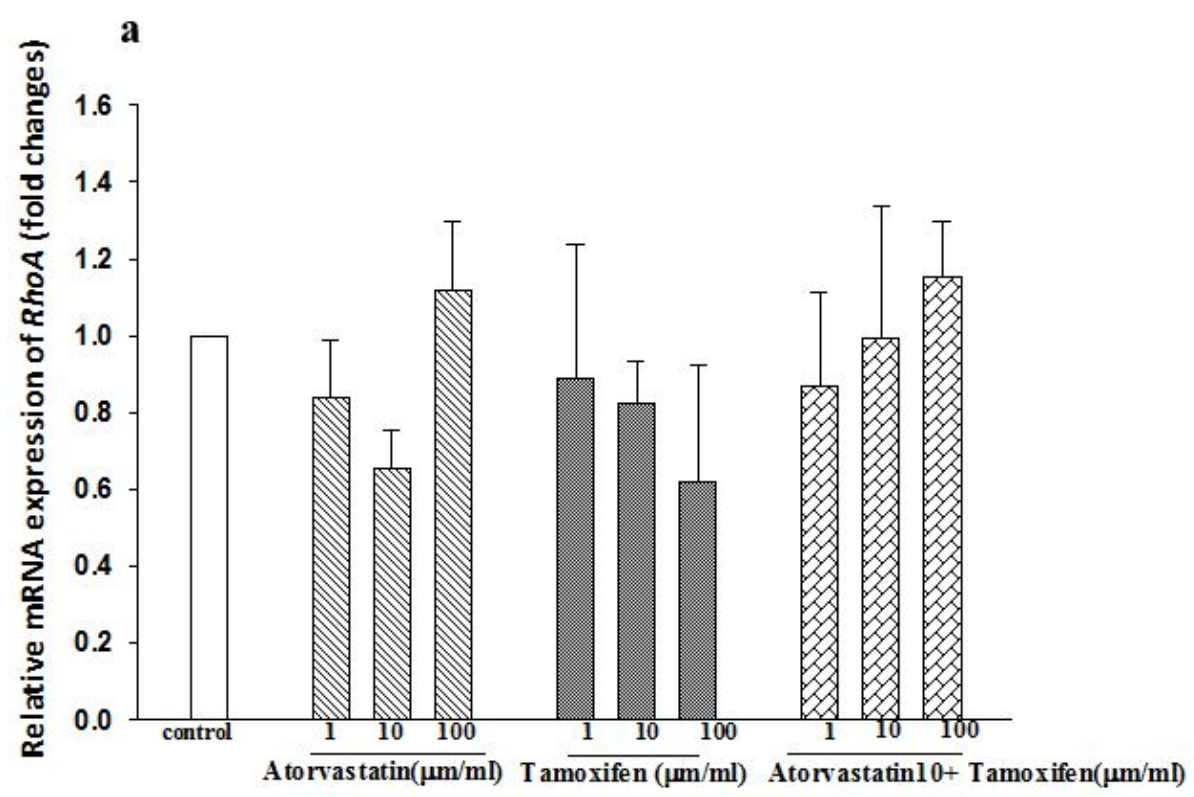

Cells after 24 hours incubation

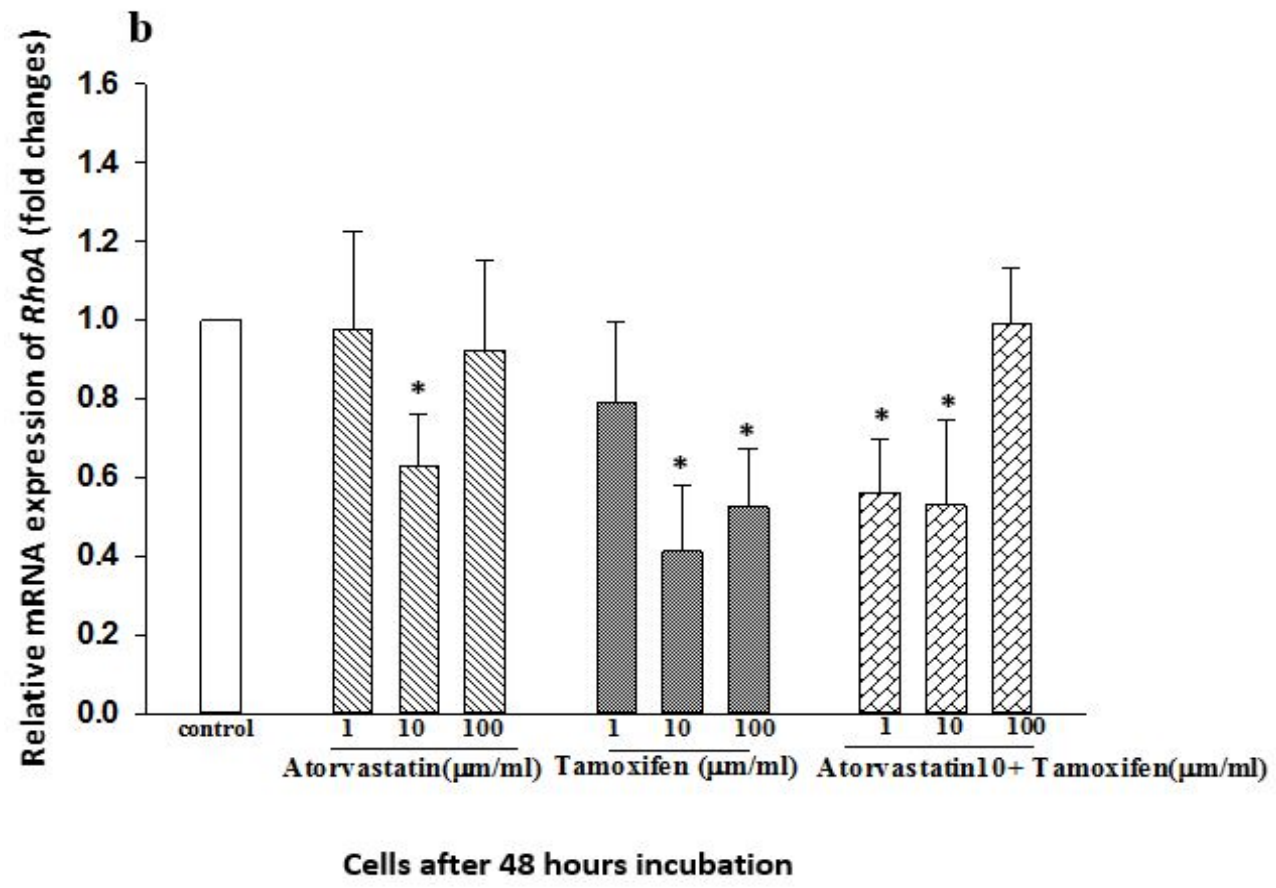

FIGURE 2. Relative mRNA expression for RhoA in B16f10 cells. Quantitative real-time PCR was used to measure RhoA abundance in cells cultures treated with atorvastatin, tamoxifen or their combination for (a) $24 \mathrm{~h}$ and (b) $48 \mathrm{~h}$. Values are expressed as fold change and $R h o A$ gene expression was determined based on the relative levels to non-treated sample (control). The relative expression levels were calculated by the $2^{-\Delta \Delta \mathrm{Ct}}$ method. In all experiments, mRNA abundance was normalized to GAPDH and represents the mean $\pm \mathrm{SEM}(\mathrm{n}=3)$. ${ }^{*} P<0.05$ compared with the control. 
melanoma might lead to an increase in outcome and response rates (Yang and Chapman, 2009). Tamoxifen exerts its antiproliferative activities via several distinct mechanisms including the up-regulation of the tumor suppressor gene TP53 which encodes p53 to promote apoptosis and cell cycle arrest (Lagadec et al., 2008). Our data showed that atorvastatin increased significantly p53 expression in combination with lower dose of tamoxifen $(1 \mu \mathrm{M} / \mathrm{ml})$. In other words, lower doses of tamoxifen are needed for inducing apoptosis in B16f10 cells due to possible potentiation by atorvastatin. Our findings are somewhat similar to other cancer types studies of statins therapy. For example, Ibrahim and colleagues (Ibrahim et al., 2019) reported that the simvastatin in combination of tamoxifen increased the apoptotic and necrotic cell death in breast cancer cells. Recently, Stine et al. (2016) have shown that simvastatin may have therapeutic benefit for ovarian cancer treatment. Statin-pretreated melanoma cells have been shown lower proliferation and viability compared to the untreated melanoma cells (Depasquale and Wheatley, 2006; Minichsdorfer and Hohenegger, 2009; Tsubaki et al., 2019). Saito et al. (2008) demonstrated anti-proliferative activity of simvastatin against melanoma cells through induction of apoptosis and cell cycle arrest.

Evidence from several studies suggests that melanoma incidence rates may be lower in patients receiving statin treatment for hypercholesterolemia (Freeman et al., 2006; von Schuckmann et al., 2020). While many cancer patients benefit from tamoxifen in both the adjuvant and metastatic settings, resistance is a notable clinical problem in a large proportion (Ring and Dowsett, 2004). On the other hand, a role of cholesterol metabolism has recently been suggested in tamoxifen resistance of cancer therapy (Hultsch et al., 2018; Tiwary et al., 2011). Therefore, a combination of statins with tamoxifen may extend the duration of tamoxifen efficacy. These medications have been proven to be safe, effective drugs with rare side effects (Armitage, 2007; Demierre et al., 2005; Law and Rudnicka, 2006). Furthermore, statins with inhibition 3-hydroxy-3-methylglutaryl-CoA reductase, a ratelimiting enzyme in the mevalonate pathway, have been shown important inhibitory effects on human melanoma cells by suppressing of cell proliferation, angiogenesis and induction of apoptosis (Altwairgi, 2015; Glynn et al., 2008). Inhibition of metabolic mevalonate pathway with essential roles in membrane formation and isoprenylation of several small GTPases seems to reduce melanoma cell growth and differentiation (Collisson et al., 2002; Ji et al., 2020; Karlic et al., 2015). Among the GTPases requiring isoprenylation are the proteins of the Rho family including RhoA, which regulate signal transduction pathway from receptors in the membrane to a broad range of cellular events, thereby acting as a molecular switch inside cells (Haga and Ridley, 2016).

The Rho family belongs to the Ras superfamily of low molecular weight GTPases and facilitates a wide spectrum of cellular functions including cell motility through organization of the actin cytoskeleton, cell cycle progression, cell death and regulation of multiple target genes transcription. Deregulation of Rho proteins is associated with oncogenic process and metastasis (Porter et al., 2016). Atorvastatin has been shown to prevent Rho geranylgeranylation and metastatic ability of melanoma cells (Collisson et al., 2003). Rho GTPases inhibitors like statins or prenylation inhibitors reduce melanoma cells migration, invasion and metastases (Clayton and Ridley, 2020; Fritz and Kaina, 2006). Our present study clearly indicated that atorvastatin suppressed RhoA expression in melanoma cell lines. It has been reported that RhoA family and their down-stream targets are essential for the regulation of G1/S transition in the cell cycle (Noguchi et al., 1998; Villalonga et al., 2006). Synergistic interaction of atorvastatin and tamoxifen may be due to the increase in apoptotic cell death in addition to other mechanisms such as decrease in ROS levels and free radical production (Ibrahim et al., 2019). Liang et al. (2017) have provided evidence that the simvastatin in combination with tamoxifen induced DNA damage, apoptosis and inhibited the growth of tamoxifen-resistant cell lines. Moreover, glucose uptake was shown to be impaired in cancer cells by statins resulted in impaired viability of tumor cells due to reduce the adaptation of tumor cells to micro-environmental conditions (Malenda et al., 2012).

\section{Conclusion}

In conclusion, atorvastatin/tamoxifen combination therapy may offer improved outcome over either single agent in melanoma chemotherapy. Atorvastatin presumably inhibit metastasis in melanoma cells through down-regulation of the RhoA expression and potentiate apoptosis via up-regulation of p53. Besides, the increased efficacy of atorvastatin/tamoxifen 
combination therapy could also reduce tamoxifen dose to minimize possible detrimental side effects in melanoma. Although our findings support the potential anticancer role of atorvastatin in melanoma cell lines, further studies will be needed to determine the in vivo and clinical efficacy of atorvastatin.

\section{Acknowledgements}

This work was supported by the Isfahan University of Medical Sciences, Isfahan, Iran (Grant No. 295230 to M.M).

\section{Conflict of interest}

The authors declare that there are no conflicts of interest.

\section{References}

Altwairgi AK. Statins are potential anticancerous agents. Oncol Rep 2015; 33: 1019-39. https://doi.org/10.3892/ or.2015.3741

Armitage J. The safety of statins in clinical practice. Lancet 2007; 370: 1781-90. https://doi.org/10.1016/S01406736(07)60716-8

Barbalata CI, Tefas LR, Achim M, Tomuta I, Porfire AS. Statins in risk-reduction and treatment of cancer. World J Clin Oncol 2020; 11: 573. https://doi.org/10.5306/wjco. v11.i8.573

Beckwitt CH, Brufsky A, Oltvai ZN, Wells A. Statin drugs to reduce breast cancer recurrence and mortality. Breast Cancer Res 2018; 20: 144. https://doi.org/10.1186/s13058018-1066-Z

Clayton NS, Ridley AJ. Targeting Rho GTPase signaling networks in cancer. Front Cell Dev Biol 2020; 8: 222. https:// doi.org/10.3389/fcell.2020.00222

Collisson EA, Carranza DC, Chen IY, Kolodney MS. Isoprenylation is necessary for the full invasive potential of RhoA overexpression in human melanoma cells. J Invest Dermatol 2002; 119: 1172-6. https://doi.org/10.1046/ j.1523-1747.2002.19519.x

Collisson EA, Kleer C, Wu M, De A, Gambhir SS, Merajver $\mathrm{SD}$, et al. Atorvastatin prevents RhoC isoprenylation, invasion, and metastasis in human melanoma cells. Mol Cancer Ther 2003; 2: 941-8.

Demierre MF, Higgins PD, Gruber SB, Hawk E, Lippman SM. Statins and cancer prevention. Nat Rev Cancer 2005; 5: 930-42. https://doi.org/10.1038/nrc1751

Depasquale I, Wheatley DN. Action of Lovastatin (Mevino- lin) on an in vitro model of angiogenesis and its co-culture with malignant melanoma cell lines. Cancer Cell Int 2006; 6: 1-2. https://doi.org/10.1186/1475-2867-6-9

Fatehi Hassanabad A. Current perspectives on statins as potential anti-cancer therapeutics: clinical outcomes and underlying molecular mechanisms. Transl Lung Cancer Res 2019; 8: 692-9. https://doi.org/10.21037/tlcr.2019.09.08

Freed-Pastor WA, Mizuno H, Zhao X, Langerød A, Moon $\mathrm{SH}$, Rodriguez-Barrueco R, et al. Mutant p53 disrupts mammary tissue architecture via the mevalonate pathway. Cell 2012; 148: 244-58. https://doi.org/10.1016/j. cell.2011.12.017

Freeman SR, Drake AL, Heilig LF, Graber M, McNealy K, Schilling LM, et al. Statins, fibrates, and melanoma risk: a systematic review and meta-analysis. J Natl Cancer Inst 2006; 98: 1538-46. https://doi.org/10.1093/jnci/djj412

Fritz G, Kaina B. Rho GTPases: promising cellular targets for novel anticancer drugs. Curr Cancer Drug Targets 2006; 6: 1-4.https://doi.org/10.2174/156800906775471752

Glynn SA, O’Sullivan D, Eustace AJ, Clynes M, O’Donovan $\mathrm{N}$. The 3-hydroxy-3-methylglutaryl-coenzyme A reductase inhibitors, simvastatin, lovastatin and mevastatin inhibit proliferation and invasion of melanoma cells. BMC Cancer 2008; 8: 9. https://doi.org/10.1186/1471-2407-8-9

Guy Jr GP, Thomas CC, Thompson T, Watson M, Massetti GM, Richardson LC. Vital signs: melanoma incidence and mortality trends and projections-United States, 1982-2030. MMWR Morb Mortal Wkly Rep 2015; 64: 591.

Haga RB, Ridley AJ. Rho GTPases: regulation and roles in cancer cell biology. Small GTPases 2016; 7: 207-21. https://doi.org/10.1080/21541248.2016.1232583

Hayashi M, Sakata M, Takeda T, Tahara M, Yamamoto T, Minekawa R, et al. Hypoxia up-regulates hypoxia-inducible factor- $1 \alpha$ expression through RhoA activation in trophoblast cells. J Clin Endocrinol Metab 2005; 90: 1712-9. https://doi.org/10.1210/jc.2004-1547

Hultsch S, Kankainen M, Paavolainen L, Kovanen RM, Ikonen E, Kangaspeska S, et al. Association of tamoxifen resistance and lipid reprogramming in breast cancer. BMC Cancer 2018; 18: 850. https://doi.org/10.1186/s12885018-4757-z

Ibrahim AB, Zaki HF, Ibrahim WW, Omran MM, Shouman SA. Evaluation of tamoxifen and simvastatin as the combination therapy for the treatment of hormonal dependent breast cancer cells. Toxicol Rep 2019; 6: 1114-26. https:// doi.org/10.1016/j.toxrep.2019.10.016

Ingallina E, Sorrentino G, Bertolio R, Lisek K, Zannini A, Az- 
zolin L, et al. Mechanical cues control mutant p53 stability through a mevalonate-RhoA axis. Nat Cell Biol 2018; 20: 28-35. https://doi.org/10.1038/s41556-017-0009-8

Ji L, Liu C, Yuan Y, Gao H, Tang Z x, Yang Z, et al. Key roles of Rho GTPases, YAP, and Mutant P53 in anti-neoplastic effects of statins. Fund Clin Pharmacol 2020; 34: 4-10. https://doi.org/10.1111/fcp.12495

Karlic H, Thaler R, Gerner C, Grunt T, Proestling K, Haider $\mathrm{F}$, et al. Inhibition of the mevalonate pathway affects epigenetic regulation in cancer cells. Cancer Genet 2015; 208: 241-52. https://doi.org/10.1016/j.cancergen.2015.03.008

Lagadec C, Adriaenssens E, Toillon R, Chopin V, Romon R, Van Coppenolle F, et al. Tamoxifen and TRAIL synergistically induce apoptosis in breast cancer cells. Oncogene 2008; 27: 1472-7. https://doi.org/10.1038/sj.onc.1210749

Law M, Rudnicka AR. Statin safety: a systematic review. Am J Card 2006; 97: S52-60. https://doi.org/10.1016/j.amjcard.2005.12.010

Liang Z, Li W, Liu J, Li J, He F, Jiang Y, et al. Simvastatin suppresses the DNA replication licensing factor MCM7 and inhibits the growth of tamoxifen-resistant breast cancer cells. Sci Rep 2017; 7: 1-11. https://doi.org/10.1038/ srep41776

Malenda A, Skrobanska A, Issat T, Winiarska M, Bil J, Oleszczak B, et al. Statins impair glucose uptake in tumor cells. Neoplasia 2012; 14: 311-23. https://doi.org/10.1593/ neo. 12444

Minichsdorfer C, Hohenegger M. Autocrine amplification loop in statin-induced apoptosis of human melanoma cells. Br J Pharmacol 2009; 157: 1278-90. https://doi. org/10.1111/j.1476-5381.2009.00298.x

Noguchi Y, Nakamura S, Yasuda T, Kitagawa M, Kohn LD, Saito Y, et al. Newly synthesized Rho A, not Ras, is isoprenylated and translocated to membranes coincident with progression of the G1 to S phase of growth-stimulated rat FRTL-5 cells. J Biol Chem 1998; 273: 3649-53. https://doi. org/10.1074/jbc.273.6.3649

Parrales A, Thoenen E, Iwakuma T. The interplay between mutant p53 and the mevalonate pathway. Cell Death Differ 2018; 25: 460-70. https://doi.org/10.1038/s41418-0170026-y

Porter AP, Papaioannou A, Malliri A. Deregulation of Rho GTPases in cancer. Small GTPases 2016; 7: 123-38. https://doi.org/10.1080/21541248.2016.1173767

Rigel DS, Carucci JA. Malignant melanoma: prevention, early detection, and treatment in the 21 st century. CA Cancer J Clin 2000; 50: 215-36. https://doi.org/10.3322/canj- clin.50.4.215

Ring A, Dowsett M. Mechanisms of tamoxifen resistance. Endocr Relat Cancer 2004; 11: 643-58. https://doi. org/10.1677/erc. 1.00776

Rivlin N, Brosh R, Oren M, Rotter V. Mutations in the p53 tumor suppressor gene: important milestones at the various steps of tumorigenesis. Genes Cancer 2011; 2: 466-74. https://doi.org/10.1177/1947601911408889

Rusthoven J. The evidence for tamoxifen and chemotherapy as treatment for metastatic melanoma. Eur J Cancer 1998; 34: 31-6. https://doi.org/10.1016/S0959-8049(97)10162-9

Saito A, Saito N, Mol W, Furukawa H, Tsutsumida A, Oyama A, et al. Simvastatin inhibits growth via apoptosis and the induction of cell cycle arrest in human melanoma cells. Melanoma Res 2008; 18: 85-94. https://doi.org/10.1097/ CMR.0b013e3282f60097

Stanisavljevic D, Petrovic I, Vukovic V, Schwirtlich M, Gredic M, Stevanovic M, et al. SOX14 activates the p53 signaling pathway and induces apoptosis in a cervical carcinoma cell line. PloS One 2017; 12: e0184686. https://doi.org/10.1371/journal.pone.0184686

Stine JE, Guo H, Sheng X, Han X, Schointuch MN, Gilliam TP, et al. The HMG-CoA reductase inhibitor, simvastatin, exhibits anti-metastatic and anti-tumorigenic effects in ovarian cancer. Oncotarget 2016; 7: 946. https://doi. org/10.18632/oncotarget.5834

Tarhini AA, Agarwala SS. Cutaneous melanoma: available therapy for metastatic disease. Dermatol Ther 2006; 19: 19-25. https://doi.org/10.1111/j.1529-8019.2005.00052.x

Tiwary R, Yu W, Linda AD, Sanders BG, Kline K. Targeting cholesterol-rich microdomains to circumvent tamoxifen-resistant breast cancer. Breast Cancer Res 2011; 13: R120. https://doi.org/10.1186/bcr3063

Toma S, Ugolini D, Palumbo R. Tamoxifen in the treatment of metastatic malignant melanoma: still a controversy? Int J Oncol 1999; 15: 321-58. https://doi.org/10.3892/ ijo.15.2.321

Tsubaki M, Takeda T, Obata N, Kawashima K, Tabata M, Imano $\mathrm{M}$, et al. Combination therapy with dacarbazine and statins improved the survival rate in mice with metastatic melanoma. J Cell Physiol 2019; 234: 17975-89. https://doi. org/10.1002/jcp. 28430

Tutuska K, Parrilla-Monge L, Di Cesare E, Nemajerova A, Moll UM. Statin as anti-cancer therapy in autochthonous T-lymphomas expressing stabilized gain-of-function mutant p53 proteins. Cell Death Dis 2020; 11: 1-12. https:// doi.org/10.1038/s41419-020-2466-4 
Villalonga P, Villalonga P, Ridley AJ. Rho GTPases and cell cycle control. Growth Factor 2006; 24: 159-64. https://doi.org/10.1080/08977190600560651

von Schuckmann LA, Khosrotehrani K, Ghiasvand R, Hughes MC, van der Pols JC, Malt M, et al. Statins may reduce disease recurrence in patients with ulcerated primary melanoma. $\mathrm{Br}$ J Dermatol 2020. https://doi.org/10.1111/bjd.19012
Watson M, Holman DM, Maguire-Eisen M. Ultraviolet radiation exposure and its impact on skin cancer risk. InSeminars in Oncology Nursing 2016; 32: 241-254. https://doi.org/10.1016/j.soncn.2016.05.005

Yang AS, Chapman PB. The history and future of chemotherapy for melanoma. Hematol Oncol Clin 2009; 23: 583-97. https://doi.org/10.1016/j.hoc.2009.03.006 